\title{
EVALUASI KONSEP PRODUK DENGAN PENDEKATAN QUALITY FUNCTION DEPLOYMENT (Studi Kasus di PT.BINTANG JAYA KLATEN)
}

\author{
Gunawan Madyono Putro'), Eko Budi Santoso ${ }^{2)}$ \\ 1,2) Jurusan Teknik Industri FTI, UPN “Veteran" Yogyakarta. \\ Jl. Babarsari no 2, Tambakbayan, Yogyakarta \\ email : bagus2007@ymail.com
}

\begin{abstract}
At the moment the wheels of vehicles continues mningkat seiiring the continued increase in the number of vehicles and the number of vehicles modified by users. so many wheels that industry continues to expand its innovation in winning the competition. Successful product is a product that can provide benefits in accordance with the perception that consumers (Baxter, 2001). In an effort to create a product that the consumer liking it is necessary to study so that the product can be marketed optimally. The method used in this study is the method of Quality Function Deployment (QFD) As for the aspects that will be discussed are covering aspects of quality , cost aspects and environmentally friendly products. These three aspects are described in their respective Quality House, QFD, and Cost House . and ntuk give weight to each aspect, the method used Analytic Hierarchy Process (AHP). From the research it can be concluded that, consumer- desired characteristics of the alloy wheels are kind of cheap, strong material, good color and interesting shape in the environmentally friendly production process .
\end{abstract}

\section{Keywords : Quality Function Deployment, Cost House , Analytic Hierarchy Process}

Saat ini kebutuhan velg kendaraan terus mningkat seiiring dengan terus bertambahnya jumlah kendaraan dan banyaknya kendaraan-kendaraan yang dimodifikasi oleh penggunanya. sehingga banyak industri velg yang terus berusaha mengembangkan inovasinya dalam memenangkan persaingan. . Produk yang sukses adalah produk yang dapat memberi manfaat sesuai dengan yang di persepsikan konsumennya (Baxter, 2001). Dalam upaya untuk mewujudkan produk yang sesuai dengan keinginan konsumen tersebut maka perlu adanya penelitian sehingga produk dapat dipasarkan secara optimal. Metode yang digunakan dalam penelitian ini adalah metode Quality Function Deployment (QFD) Adapun aspek-aspek yang akan dibahas adalah meliputi aspek kualitas, aspek biaya dan produk ramah lingkungan. Ketiga aspek tersebut masing-masing dijabarkan dalam Quality House, QFD, dan Cost House. dan ntuk memberi bobot pada tiap aspek, digunakan metode Analitic Hierarchy Process (AHP). Dari hasil penelitian dapat diambil kesimpulan bahwa, karakteristik velg yang diingini komsumen adalah jenis velg yang murah, bahannya kuat, warnanya menarik bentuknya bagus dan ramah lingkungan dalam proses produksinya.

Kata Kunci : Quality Function Deployment, Cost House, Analitic Hierarchy Process.

\section{LATAR BELAKANG}

PT. Bintang Jaya merupakan sebuah perusahaan yang bergerak dalam bidang pengerjaan logam khususnya pembuatan velg motor. Saat ini PT. Bintang Jaya selalu melakukan inovasi- inovasi dalam proseses produksinya untuk memenuhi keinginan pasar. Saat ini permintaan pasar banyak yang menginginkan agar velg yang dihasilkan selain berkualitas juga ramah lingkungan, sehingga perlu dilakukan penelitian untuk memenuhi permintaan konsumen tersebut. Ada beberapa metode yang dapat dipakai untuk menganalisis keinginan konsumen, di dalam QFD (Quality Function Deployment) klasik yang diciptakan oleh Akao (Akao, 1991) bisa mengintegrasikan masalah lingkungan. Namun menurut Zhang (1999) QFD masih belum efisien karena masih belum mempertimbangkan biaya di dalam matriksmatriksnya.

Pada tahun 1998, Zhang mulai melakukan pengembangan QFD sehingga mampu menciptakan QFD II. Metode QFD ini tidak hanya mempertimbangkan aspek kualitas tetapi juga memperhatikan aspek lingkungan dan biaya ke dalam matriks-matriksnya. Ketiga aspek 
tersebut masing-masing dijabarkan dalam House Of Quality, Quality House, dan Cost House. Untuk memberi bobot pada tiap aspek, pada penelitian ini digunakan metode Analitic Hierarchy Process. Pada QFD ini, untuk mengevaluasi konsep produk digunakan matriks Concept Comparison House $(\mathrm{CCH})$ yang mampu mengintegrasikan aspek kualitas, lingkungan, dan biaya.

\section{TUJUAN PENELITIAN}

Adapun tujuan dari penelitian ini adalah:

1. Mengetahui kriteria-kriteria kebutuhan dan keinginan konsumen (costumer needs and wants) dari velg motor.

2. Melakukan perbandingan kriteria dengan menggunakan Analitycal Hierarcy Proces

\section{METODOLOGI PENELITIAN}

3.1. Pembuatan matriks house of quality (HOQ)

Dalam pembuatan matriks $\mathrm{HOQ}$ yang pertama harus dilakukan adalah melakukan interview kepada konsumen untuk mendapatkan Voice of Costumer (VOC)

1. Hasil Voice of Costumer (VOC) yaitu:
a. Awet/tahan lama
b. Ringan
c. Harga terjangkau
d. Model terbaru
e. Kuat
f. Warna variatif
g. Mudah didapat
h. Mudah dalam pemasangan
i. Bergaransi
j. Merk terkenal
2. Karakteristik teknis, antara lain:
a. Kualitas bahan baku
b. Harga jual
c. Jaringan pemasaran luas
d. Keringanan bahan
e. Kekuatan bahan

\section{2. Pembuatan matriks Quality Function Deployment}

Untuk pembuatan matriks Quality Function Deployment, peneliti mencari informasi melelui perusahaan tentang dampak-dampak lingkungan yang disebabkan proses produksi logam khususnya pembuatan velg motor.

\section{3. Pembuatan matriks cost house}

Sedangkan untuk pembuatan matriks cost house, peneliti menanyakan kepada pihak perusahaan mengenai biaya-biaya yang harus dikeluarkan perusahaan untuk memproduksi velg motor serta biaya yang dikeluarkan untuk menangani limbah yang dihasilkan saat proses produksi berlangsung.

4.4. Perhitungan AHP

AHP digunakan untuk mengetahui riteria-kriteria mana yang harus di dahulukan oleh perusahaan dalam proses pengerjaan velg, sehingga antara keinginan konsumen dan faktor biaya yang ada pada perusahaan dapat tercapai.

\subsection{Kerangka Penelitian} gambar 1.

Agar penelitian berjalan secara sistemis, maka langkah-langkah penelitian seperti 


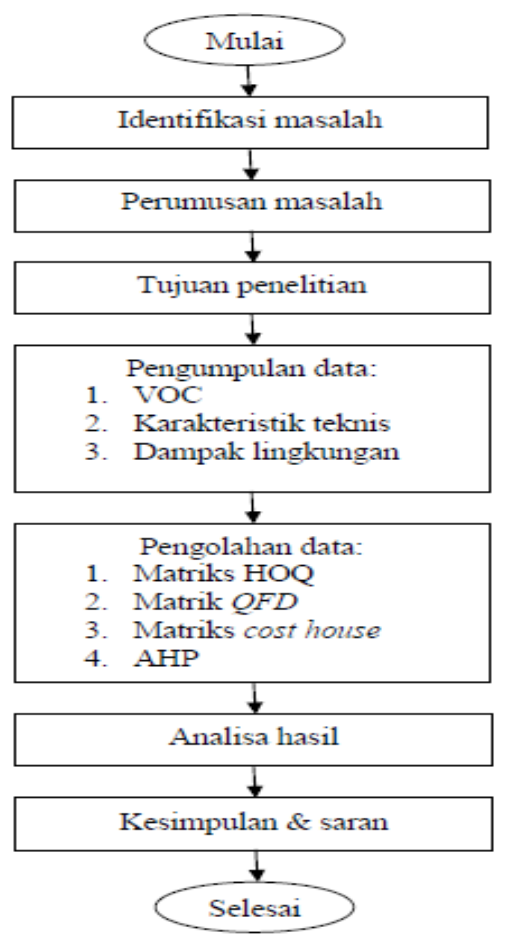

Gambar 1. Kerangka penelitian

\section{ANALISIS DAN PEMBAHASAN}

\subsection{Pembuatan matrik $\mathrm{HOQ}$}

Tabel 1. VOC dan karakteristik Teknik

\begin{tabular}{|c|c|c|c|c|c|c|}
\hline What & How & $\begin{array}{l}\text { Kebutuhan } \\
\text { bahan } \\
\text { baku }\end{array}$ & Harga jadi & $\begin{array}{l}\text { Jaringan } \\
\text { pemasaran }\end{array}$ & $\begin{array}{l}\text { keringanan } \\
\text { bahan }\end{array}$ & $\begin{array}{l}\text { Kekuatan } \\
\text { bahan }\end{array}$ \\
\hline Awet & 8 & $x$ & & & & $x$ \\
\hline Warna inovatif & 5 & & & & & \\
\hline $\begin{array}{l}\text { Mudah } \\
\text { didapatkan }\end{array}$ & 9 & & & $x$ & & \\
\hline $\begin{array}{l}\text { Mudah } \\
\text { dipasang }\end{array}$ & 9 & - & & & $x$ & \\
\hline $\begin{array}{l}\text { Harga } \\
\text { terjangkau }\end{array}$ & 9 & + & $x$ & & & + \\
\hline Garansi & 8 & & $x$ & & & \\
\hline $\begin{array}{l}\text { Bentuk } \\
\text { menarik }\end{array}$ & 8 & + & & & & + \\
\hline Merk terkenal & 5 & $x$ & $x$ & + & & \\
\hline
\end{tabular}

Keterangan:

x 9 hubungan kuat

$+\quad 3$ hubungan sedang

1 hubungan kecil

Sedangkan untuk angka 8, 5, 9, 9, 9, 8, 8, 5 itu adalah ditentukan oleh peneliti seberapa kuat nilai yang diharapkan terhadap keinginan dari konsumen untuk VOC dapat dipenuhi. Artinya nilai 9 maksudnya adalah nilai prioritas tertinggi yang, dan jika nilainya semakin turun maka prioritasnya semakin turun juga. Untuk hal ini skala nilai yang digunakan adalah 1-9, dan nilai 1 adalah nilai terendah yang jadi prioritas dari keinginan konsumen. 
Tabel 2. Hasil VOC dan QFD

\begin{tabular}{|c|c|c|c|c|c|c|}
\hline WHAT & HOW & Kualitas bahan baku & Harga jual & $\begin{array}{c}\text { Jaringan } \\
\text { pemasaran luas }\end{array}$ & Keringanan bahan & Kekuatan bahan \\
\hline awet & 8 & 72 & & & & 72 \\
\hline Warna variatif & 5 & & & & & \\
\hline $\begin{array}{c}\text { Mudah } \\
\text { didapatkan }\end{array}$ & 9 & & & 81 & & \\
\hline Mudah dipasang & 9 & 9 & & & 81 & \\
\hline Harga terjangkau & 9 & 27 & 81 & & & 27 \\
\hline Garansi & 8 & & 72 & & & \\
\hline Bentuk menarik & 8 & 24 & & & & 24 \\
\hline Merk terkenal & 5 & 45 & 45 & 15 & & 45 \\
\hline & JUMLAH & 177 & 198 & 96 & 81 & 168 \\
\hline & PRIORITAS & 2 & 1 & 4 & 5 & 3 \\
\hline
\end{tabular}

4.2. Hubungan teknis

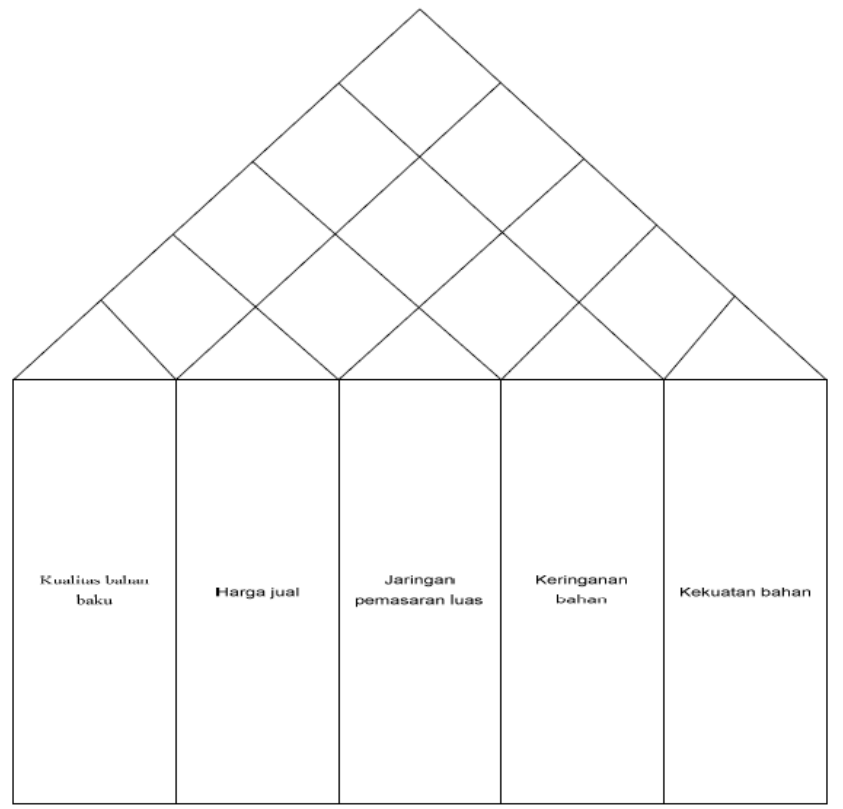

Gambar 2. Hubunaan karakteristik teknis

4.3. Pembuatan matrik cost hause

Tabel 3. Matrik cost hause

\begin{tabular}{|c|c|c|c|c|c|c|c|c|c|}
\hline & \multicolumn{3}{|c|}{ Proses produksi } & \multicolumn{2}{|l|}{ Pengolahan limbah } & \multicolumn{2}{|c|}{ Distribusi \& servis } & \multicolumn{2}{|c|}{ Biaya bagi user } \\
\hline & $\begin{array}{l}\text { Bahan } \\
\text { baku } \\
\text { langsung }\end{array}$ & $\begin{array}{l}\text { Tenaga } \\
\text { kerja } \\
\text { langsung }\end{array}$ & overhead & Operasi/maintenence & energi & transportasi & $\begin{array}{l}\text { Tenaga } \\
\text { kerja }\end{array}$ & pembelian & $\begin{array}{l}\text { Spare } \\
\text { part }\end{array}$ \\
\hline & 13,82 & 691 & 1,383 & 166 & 608 & 16 & 5 & 32 & 9,47 \\
\hline & ++ & + & ++ & + & + & + & + & & + \\
\hline & - & - & & & & & & & \\
\hline & - & - & & & & & & & - \\
\hline & + & & & - & -- & & & & ++ \\
\hline JUMLAH & $3+1-$ & $1+2-$ & $2+$ & $1+1-$ & $1+1-$ & $1+$ & $1+$ & & $3+1-$ \\
\hline PRIORITAS & 6 & & 7 & & & 5 & 4 & & 8 \\
\hline
\end{tabular}

Keterangan relation matrik:

-- Pengaruh negatif besar

- $\quad$ Pengaruh negative sedang

$<$ kosong $>$ Pengaruh positip kecil

$+\quad$ Pengaruh positip sedang

$++\quad$ Pengaruh positip besar 
4.4. Perhitungan AHP dengan cara manual dan menggunakan software expert choice

Pembobotan AHP digunakan untuk menentukan tingkat kepentingan suatu kriteria. Terdapat 3 jenis kuisioner AHP, yaitu kuisioner AHP untuk menentukan pembobotan perspektif kualitas, pembobotan di perspektif lingkungan, pembobotan di perspektif biaya. Menurut Cohen, L., 1995, suatu kuisioner pembobotan AHP akan dianggap konsisten, jika nilai Consistency Ratio kurang dari 0,1 (10\%). Jika nilai Consistency Ratio kurang dari 0,1 terpenuhi maka nilai pembobotan AHP dapat digunakan sebagai nilai bobot kriteria. Berikut merupakan contoh perhitungan perhitungan manual pembobotan AHP pada 3 perspektif yang digunakan.

Tabel 4. Bobot kriteria

\begin{tabular}{|l|l|l|l|}
\hline & kualitas & Karakteristik velg & biaya \\
\hline Kualitas & 1 & 2 & 3 \\
\hline Karakteristik velg & $1 / 2$ & 1 & 2 \\
\hline biaya & $1 / 3$ & $1 / 2$ & 1 \\
\hline
\end{tabular}

Tabel 5. Desimal Ekivalen

\begin{tabular}{|l|l|l|l|}
\hline & kualitas & karakteristik teknis & biaya \\
\hline Kualitas & 1 & 2 & 3 \\
\hline karakteristik teknis & 0.5 & 1 & 2 \\
\hline biaya & 0.3 & 0.5 & 1 \\
\hline jumlah & 1.8 & 3.5 & 6 \\
\hline
\end{tabular}

Tabel 6. Normalisasi

\begin{tabular}{|l|l|l|l|l|l|}
\hline & kualitas & $\begin{array}{l}\text { karakteristik } \\
\text { teknis }\end{array}$ & biaya & Jumlah & $\begin{array}{l}\text { Rata- } \\
\text { rata }\end{array}$ \\
\hline Kualitas & 0.55 & 0.57 & 0.5 & 1.62 & 0.54 \\
\hline karakteristik teknis & 2.3 & 0.28 & 0.33 & 2.91 & 0.97 \\
\hline biaya & 0.16 & 0.14 & 0.16 & 0.46 & 0.15 \\
\hline jumlah & 3.01 & 0.99 & 0.99 & 4.99 & \\
\hline
\end{tabular}

Tabel 7. Jumlah nilai yang paling besar dan bobot prioritas

\begin{tabular}{|l|c|c|}
\hline & Jml nilai yang paling besar & Bobot prioritas \\
\hline Kualitas & 0,57 & $0,57 / 3=0,19$ \\
\hline Karakteristik Teknis & 2,3 & $2,3 / 3=0,76$ \\
\hline Biaya & 0,16 & $0,16 / 3=0,05$ \\
\hline
\end{tabular}

Sedangkan bila menggunakan software expert choice didapatkan hasil sebagai berikut :

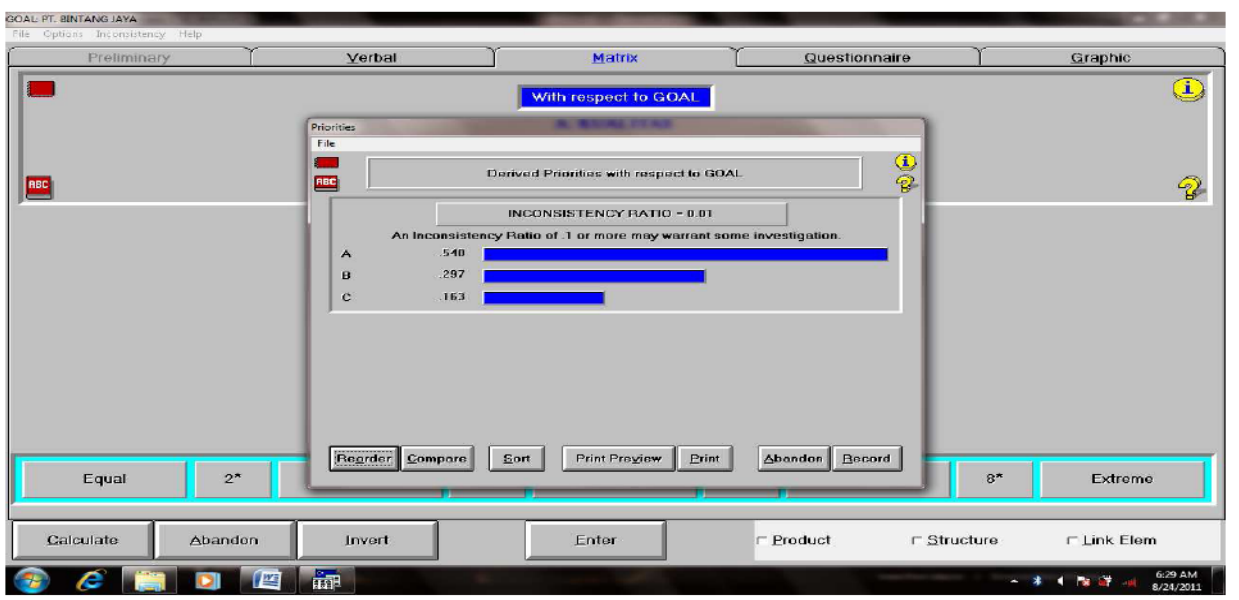

Gambar 3. Tahap 5 pembuatan AHP dengan expert choice 


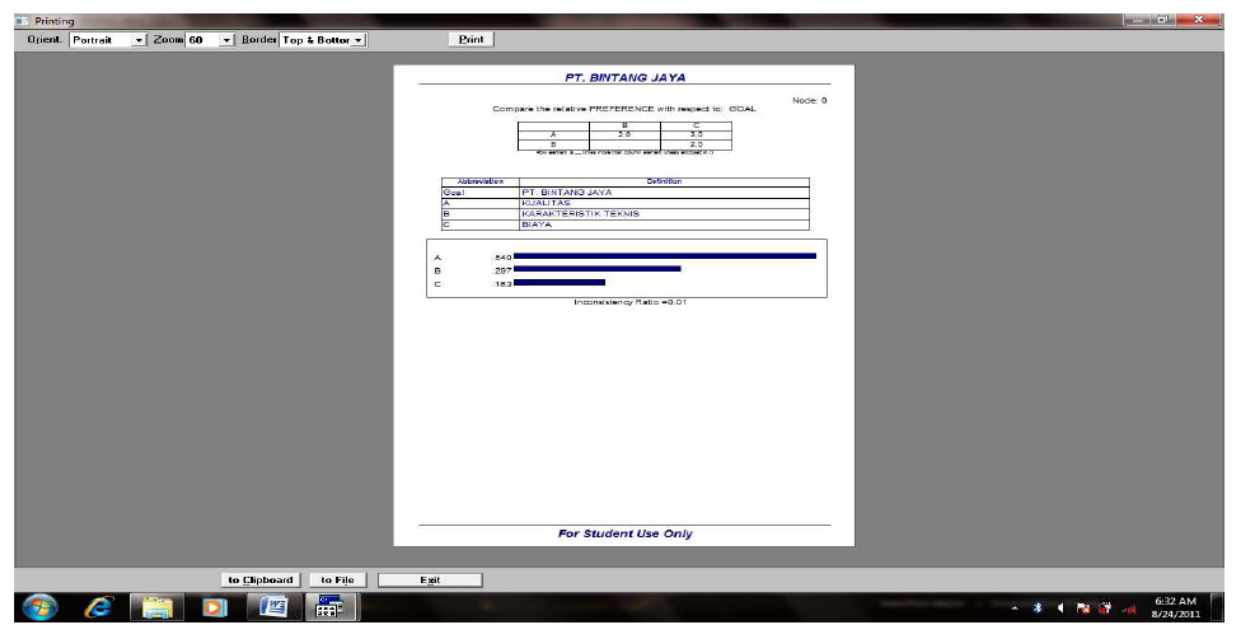

Gambar 4. Tahap 5 pembuatan AHP dengan expert choice

\section{ANALISA HASIL}

Bobot QEC (Quality, Environment, Cost) ditetapkan dengan menggunakan metode Analytic Hierarchy Process. Kolom kepuasan menunjukkan nilai performansi konsep produk dilihat dari perspektif kualitas, karakteristik teknis, dan biaya. Hasil evaluasi dengan menggunakan QFD ini dapat diketahui bahwa pengembangan HOQ dan QFD dapat digunakan sebagai alat untuk desain dan pengembangan produk baru. Kemampuan QFD dalam mengintegrasikan kualitas, karakteristik teknis, dan biaya ke dalam satu matriks yaitu matriks Concept Comparison House.

Penggunaan expert choice sangat membantu dan menentukan untuk mendapatkan bobot kepentingan dari setiap KPIs yang dicari, sehingga dari pembobotan tersebut dapat dijadikan acuan bagi PT. Bintang Jaya dalam merancang sekaligus mengevaluasi kinerja perusahaan. Misalnya dari perhitungan dengan expert choice diatas dapat diketahui unruk perspektif kualitas memiliki bobot nilaisebesar 0.540 yang artinya faktor kualitas sangat signifikan bagi perusahaan dalam mengukur kinerjanya, sedangkan perspektif karakteristik teknis memiliki nilai sebesar 0.297 yang artinya perspektif karakteristik teknis menjadi nomor 2 dalam usaha perusahaan untuk meningkatkan kinerjanya, sedangkan perspektif biaya menjadi nomor 3 yang harus di perhatikan perusahaan dengan bobot nilai sebesar 0.163.

\section{KESIMPULAN}

Dari hasil pemilihan konsep produk berdasar kriteria QEC (Quality, Environment, Cost), dapat diambil keputusan, karakteristik velg yang memenuhi kriteria konsumen serta dengan memperhatikan faktor kualitas, karakteristik teknis, dan biaya adalah velg yang awet, murah, bahannya kuat, warnanya menarik, dan memenuhi keinginan dari konsumennya dalam proses produksinya. Untuk meraih karakteristik tersebut, produsen sebaiknya memperhatikan faktorfaktor penyebabnya. Elemen biaya yang terjadi selama siklus hidup produk yang dimungkinkan dapat mendukung cost reduction programme adalah biaya overhead.

\section{DAFTAR PUSTAKA}

Akao, Y., 1991. Quality function Deployment: Integrating Costumer Requiremnts Into Product Design, Productivity Press. Portland, Oregon

Cohen, L., 1995. Quality function Deployment: How To Make QFD Work For You, Addison wisely publishy company.

DeMendonça, M., and T.E. Baxter, 2001. "Design for the environment (DFE): An Approach to achieve the ISO 14000 international standardization", Environmental Management and Health, Vol. 12 No. 1, pp. 51-56.

Dong, C., C. Zhang, and B. Wang, 2001. "Integration of green quality function deployment and fuzzy multiattribute utility thoery-based cost estimation for environmentally conscious product development", International Journal of Environmentally Conscious Design \& Manufacturing. 